\title{
Effect of Chitosan/BSA Addition on the Physical Stability of Sunflower Oil Emulsions
}

\author{
Fengyan Zhou $\mathbb{D}^{1},{ }^{1}$ Guo $\mathrm{Li}^{2}$ and Jianying Huang $\mathbb{D}^{2}$ \\ ${ }^{1}$ College of Material Chemistry and Chemical Engineering, Zaozhuang University, Zaozhuang 277160, China \\ ${ }^{2}$ College of Food Science and Biotechnology, Zhejiang Gongshang University, Hangzhou 310018, China \\ Correspondence should be addressed to Jianying Huang; huangjy@mail.zjgsu.edu.cn
}

Received 10 April 2019; Revised 28 May 2019; Accepted 10 June 2019; Published 1 July 2019

Academic Editor: Antoni Szumny

Copyright (C) 2019 Fengyan Zhou et al. This is an open access article distributed under the Creative Commons Attribution License, which permits unrestricted use, distribution, and reproduction in any medium, provided the original work is properly cited.

Proteins and polysaccharides are important ingredients and additives in food field. The aim of this study was to study the effect of chitosan and bovine serum albumin (BSA) solution on the physical stability of sunflower oil emulsions at different $\mathrm{pH}$ values, temperatures, and BSA/chitosan ratios during 20-day storage in terms of their storage stability, zeta potential, particle size, and microstructure. The results showed that $\mathrm{pH}$, protein/polysaccharide ratio, and temperature significantly influenced the physical stability of emulsions at lower $\mathrm{pH}$. The emulsion stability decreased as the test temperatures increased, and the storage stability of $\mathrm{BSA} /$ chitosan coated oil emulsions was obtained when the ratio was from $8: 1$ to $1: 1$ under $4^{\circ} \mathrm{C}$ for 20 -day storage when $\mathrm{pH}$ values were 3.0 and 4.0. Droplet flocculation happened with the increase of chitosan addition and $\mathrm{pH}$ value.

\section{Introduction}

Oil-in-water emulsions, heterogeneous systems with liquid droplet dispersion in nonmiscible or partly miscible liquid, have potential utilization in food, pharmaceutical, and personal care product applications [1]. However, the physical stability of emulsion systems will breakdown over time because of some physicochemical mechanisms including creaming, flocculation, coalescence, phase inversion, and Ostwald ripening [2]. In order to kinetically stabilize the emulsions, some amphiphilic polymers and surfactants are used to reduce interfacial tension and exert electrostatic repulsion and/or steric hindrance between pairs of dispersed droplets [3]. However, the use of synthetic surfactants in the food system is limited because of public health concern [4]. Therefore, the study of the label-friendly natural alternatives, such as biological macromolecules (e.g., proteins and chitosan), has been paid more attention.

Although proteins facilitate emulsion formation and can increase its physical stability [5], the emulsification activity of proteins will decrease close to the protein isoelectric point $(\mathrm{pI})$, and proteins are less stable under further processing conditions [6]. The electrostatic and steric interactions between protein hydrophobic part and hydrophilic polysaccharides make them better attached to the oil droplet surface, thereby improving the stability of the emulsion system $[7,8]$. Therefore, the physical stability of emulsion by polysaccharide and protein addition has been well studied using different polysaccharides, such as neutral polysaccharide (hydroxyethylcellulose and dextran) and anionic polysaccharide (carrageenan, alginate, and carboxymethylcellulose) $[9,10]$.

Chitosan, a natural cationic polysaccharide, has been used as a food additive and food processing aid because of its inexpensive, nontoxic properties and potential health benefits [11]. Nonetheless, few studies on its stabilizing role in the protein-based model emulsion system were reported, and less information on the mechanism of $\mathrm{O} / \mathrm{W}$ emulsions stabilized by chitosan and protein under different environmental conditions could be obtained.

Additionally, bovine serum albumin (BSA) has been widely studied as an emulsifier for decades because of the well-characterized and well-known physicochemical properties $[12,13]$. Very recently, we found that $\mathrm{pH}$ and chitosan/ BSA ratio significantly influenced the interaction between these two biomolecules [14]. 
Herein, the behavior of sunflower oil emulsion in the presence of various BSA/chitosan ratios under different $\mathrm{pH}$ and temperature conditions is examined in terms of their storage stability, zeta potential, particle size, and microstructure.

\section{Materials and Methods}

2.1. Materials. BSA $(98 \%, 66.4 \mathrm{kDa})$ was purchased from Bailingwei Chemical Technology Co., Ltd. (Shanghai, China). Water-soluble chitosan (WSC; water-soluble chitosan hydrochloride) with the deacetylation of $92 \%$ and a centipoise viscosity of $22 \mathrm{mPa} \cdot \mathrm{s}\left(1 \%, 20^{\circ} \mathrm{C}\right)$ was afforded by Qingdao Honghai Biotechnology Company (Shandong, China). Sunflower oil (containing $13.0 \mathrm{~g} / 100 \mathrm{~g}$ of saturated polyunsaturated fats, $26.4 \mathrm{~g} / 100 \mathrm{~g}$ of monounsaturated polyunsaturated fats, and $60.5 \mathrm{~g} / 100 \mathrm{~g}$ of polyunsaturated fats) was bought from the Hanghzou supermarket.

2.2. Preparation of Emulsions. BSA was separately dissolved in acetate buffer solutions with different $\mathrm{pH}$ values $(\mathrm{pH}$ $3.0-7.0,0.1 \mathrm{~mol} / \mathrm{L})$ to afford a series of concentration solution $(0.01875 \%-2.4 \%, \mathrm{w} / \mathrm{v})$. An appropriate amount of chitosan was dissolved in acetic acid ( $\mathrm{pH} 3.0-7.0,0.1 \mathrm{~mol} / \mathrm{L})$. The protein-chitosan solution ( $R=$ BSA : WSC, $8: 1-1: 8$, w/ $\mathrm{w})$ was prepared by mixing appropriate amounts of chitosan and protein in acetate buffer solutions ( $\mathrm{pH} 3.0-7.0,0.1 \mathrm{~mol} /$ L). Then sodium azide $(0.02 \% \mathrm{w} / \mathrm{v})$ was added as antimicrobial agent. The continuous phase solutions were adjusted to the desired $\mathrm{pH}$ using sodium hydroxide or hydrochloric acid solutions with gentle stirring at room temperature for $4 \mathrm{~h}$ and then kept overnight at $4^{\circ} \mathrm{C}$. Then, an oil-in-water emulsion was prepared by mixing $5 \% \mathrm{v} / \mathrm{v}$ sunflower oil into the above continuous phase solutions, using a high-speed blender (IKA-Ultra-Turrax T18 equipped with a S18N-19G dispersing tool, Germany) and was operated at $11000 \mathrm{rpm}$ for $2 \mathrm{~min}$ to form a coarse emulsion. Subsequently, the coarse emulsion was passed through a high-pressure homogenizer (APV-1000, Denmark) twice under $30 \mathrm{MPa}$ at ambient temperature. The resulting emulsions were stored at $4^{\circ} \mathrm{C}$ until further analysis.

2.3. Storage Stability. For the thermal stability test, emulsions were transferred into $10 \mathrm{~mL}$ colorless glass bottles and then, respectively, stored at $4^{\circ} \mathrm{C}, 25^{\circ} \mathrm{C}$, and $37^{\circ} \mathrm{C}$ for 20 days. The $\mathrm{pH}$ stability test was performed by adjusting the $\mathrm{pH}$ of the emulsions to $3.0,4.0,5.0,6.0$, and 7.0 using $0.1 \mathrm{~mol} / \mathrm{L}$ sodium hydroxide or hydrochloric acid solutions. The storage stability of the emulsion samples was monitored by visual observation of the height of aqueous phase formed at the bottom of the bottles.

2.4. Zeta Potential Measurements. The zeta potential of the emulsions was determined using a particle electrophoresis instrument (Zetasizer Nano-ZS, Malvern Instruments, Worcestershire, UK). Emulsion samples were diluted to a concentration of approximately $0.01 \% \mathrm{w} / \mathrm{w}$ using acetate buffer solutions with corresponding $\mathrm{pH}$ value to avoid multiple scattering effects. Samples were equilibrated for $60 \mathrm{~s}$ inside the instrument before data were collected over at least 12 sequential readings. The calculated electrophoretic mobility is converted into zeta potential values using the Smoluchowski model [15]. All measurements were conducted in triplicate.

2.5. Particle Size Measurements. The mean particle diameter and droplet size distribution of the emulsions were measured by laser light diffraction using a Nanoseries ZS instrument (Zetasizer Nano-ZS, Malvern Instruments, Worcestershire, UK) according to the literature [16]. Emulsion samples were diluted 1:100 using the acetate buffer solutions of the appropriate $\mathrm{pH}$ to avoid multiple scattering effects. Samples were equilibrated for $60 \mathrm{~s}$ inside the instrument before data were collected for at least 12 sequential readings. All measurements were made in triplicate.

2.6. Light Microscopy Observations. Emulsion droplets were visualized using an optical microscope (Nikon Eclipse E100, Jiangnan Yongxin Optical Co. Ltd., Nanjing) with a 40× objective lens (NA 0.65). The emulsions were diluted $(1: 1)$ using acetate buffer solution and gently stirred in a glass test tube to ensure their homogeneity. Then emulsion droplets were placed directly onto a glass microscope slide and were captured by an Olympus BX 51 optical microscope fitted with a digital camera (Olympus, DP50).

2.7. Statistical Analysis. All experiments were carried out in duplicate using freshly prepared emulsion samples, and all measurements were performed three times. Results are reported as the calculated means and standard deviations.

\section{Results and Discussion}

3.1. Optimization of Emulsion Preparation Conditions. Initially, a series of different concentrations of BSA were used as an emulsifier to obtain the optimal protein concentration in the sunflower oil emulsion system (5\% v/v oil, $\mathrm{pH}$ 7.0). The examinations of the influence of different BSA concentrations on the mean particle diameter and droplet size distribution of emulsions are presented in Figure 1. As expected, the mean particle diameter of emulsion droplets decreased with the increase of protein concentration. The emulsifier concentration dependence of mean droplet diameter can be conveniently attributed to higher emulsifier concentration and larger surface area, leading to faster coverage of the droplet surfaces and against coalescence. This observation is consistent with the study reported by Yuan et al. [6]. The inset optical microscopy image of sunflower oil emulsion in Figure 1(a) further confirmed this observation. Emulsion prepared with $0.01875 \% \mathrm{w} / \mathrm{v}$ BSA yielded large droplets with the mean particle diameter $7297.6 \mathrm{~nm}$, while the volume mean particle diameters were $481.7 \mathrm{~nm}$ when the concentration of BSA was $0.15 \% \mathrm{w} / \mathrm{v}$. No 


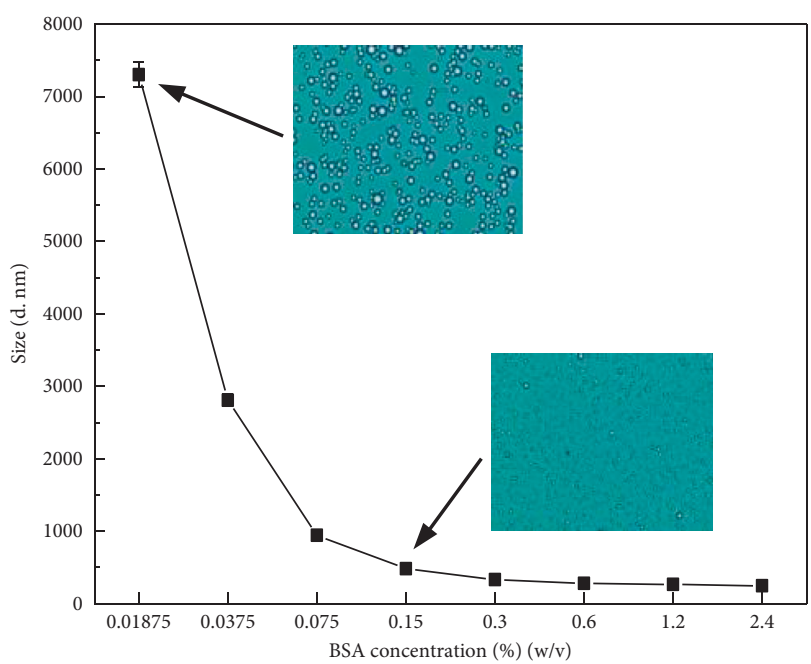

(a)

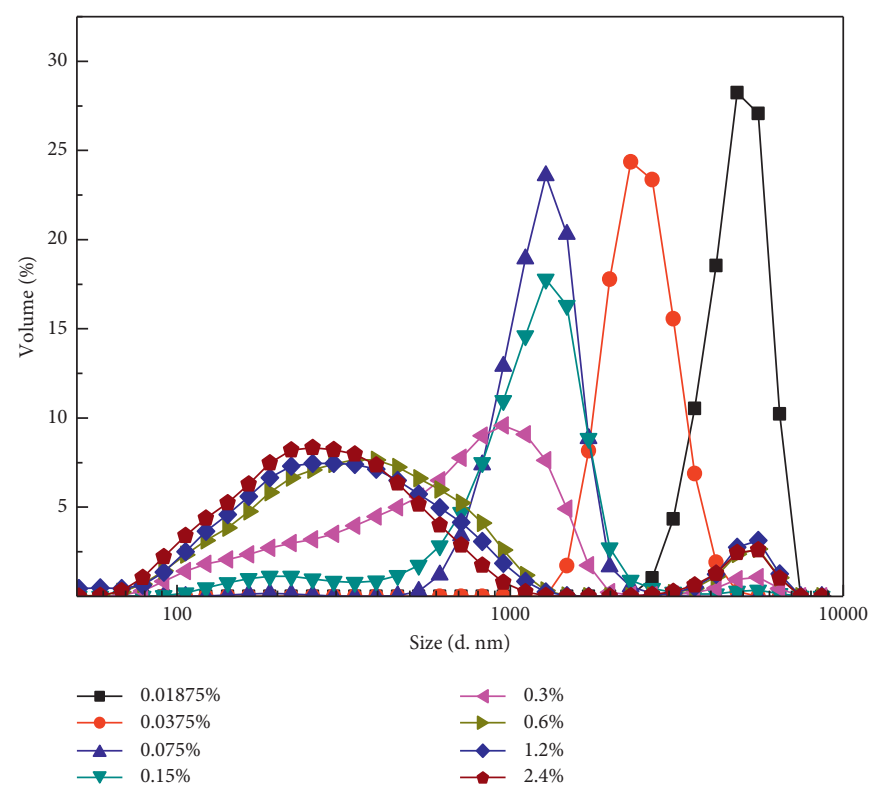

(b)

FIGURE 1: Influence of BSA concentration on mean particle diameter (a) and droplet size distribution (b) of emulsions (5\% v/v oil, $\mathrm{pH} 7.0$ ).

large droplets were observed in the optical microscopy images in this regimen (Figure 1(a), inset).

According to the theory described by Tcholakova et al. $[17,18]$, from $0.01875 \%$ to $0.075 \% \mathrm{w} / \mathrm{v}$ of BSA concentration, emulsion with large droplets is the "emulsifier-limited zone," while from $0.15 \%$ to $2.4 \% \mathrm{w} / \mathrm{v}$ of BSA concentration, emulsion with smaller droplets is the "emulsifier-rich zone." Larger emulsion droplets were much less stable under low shear by mixing compared with the smaller droplets formed at higher BSA concentrations because of the larger surface area and the faster coverage of the droplet surfaces $[19,20]$. Therefore, $0.15 \% \mathrm{w} / \mathrm{v}$ of BSA concentration was supposed to be critical emulsifier concentration where the droplets were fully saturated with protein and a marked change occurred in the slope of the mean diameter corresponding to BSA concentration curves (Figure 1). Thus, $0.15 \% \mathrm{w} / \mathrm{v}$ of BSA concentration was fixed in subsequent investigation.

\subsection{Storage of Chitosan/BSA Stabilized Sunflower Oil} Emulsions. Addition of ionic polysaccharides to emulsions containing protein-coated lipid droplets may either increase or decrease their physical stability, depending on the nature of the interactions involved $[8,21,22]$. With the optimal BSA concentration at hand, sunflower oil emulsions were formulated at a $1 / 19$ ratio $(\mathrm{O} / \mathrm{W})$, with different ratios of $\mathrm{BSA}$ : WSC in the water phase. And then, the prepared emulsions were specifically studied under diverse factors, i.e., temperatures and $\mathrm{pH}$ values which might influence the stability of emulsions.

Effects of $\mathrm{pH}$ on the 20-day storage of emulsions stabilized by $0.15 \% \mathrm{w} / \mathrm{v}$ of BSA and by different ratios of BSA/ WSC are presented in Figures 2 and 3. It can be obviously observed that the BSA-stabilized emulsions were stable under $\mathrm{pH} 3.0$ and 4.0, while light syneresis appeared in the

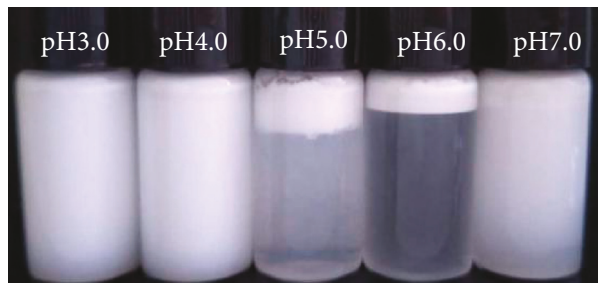

Figure 2: Photographs of BSA-stabilized emulsions (containing $0.15 \% \mathrm{w} / \mathrm{v} \mathrm{BSA}$ and $5 \% \mathrm{v} / \mathrm{v}$ oil with different $\mathrm{pH}$ values) after 20 -day storage at $25^{\circ} \mathrm{C}$.

emulsions of $\mathrm{pH} 7.0$ and $25^{\circ} \mathrm{C}$ storage condition. However, serious creaming was observed in the emulsions of $\mathrm{pH} 5.0$ and 6.0. The aggregates formed at $\mathrm{pH}>\mathrm{pKa}$ have been found to have higher affinity to oil as a result of enhanced hydrophobicity, while flocculation or coalescence of BSAcoated oil droplets happened because of lower electrostatic mutual repulsion when the $\mathrm{pH}$ value approached the isoelectric point of BSA ( $\mathrm{p} I$ 4.7).

As shown in Figure 3(a), the freshly prepared sunflower oil emulsions with different ratios of BSA/WSC and different $\mathrm{pH}$ values were homogeneous. It is noted that the emulsions stabilized by the BSA/WSC ratios from $8: 1$ to $1: 1$ at $\mathrm{pH} 3.0$ and by BSA/WSC ratios from $8: 1$ to $1: 2$ at $\mathrm{pH} 4.0$ were stable after 20-day storage at $25^{\circ} \mathrm{C}$ (Figures $3(\mathrm{~b})$ and $3(\mathrm{c})$ ). Obviously, flocculation or coalescence of BSA/WSC-coated oil droplets was observed in other BSA/WSC emulsions (Figures 3(b)$3(\mathrm{f})$ ). It can be concluded that chitosan addition influences the $\mathrm{O} / \mathrm{W}$ emulsion stability at different $\mathrm{pH}$ values. Phase separation appeared in the high concentration of WSC $(R \leq 1: 2)$ at $\mathrm{pH} 3.0$ and 4.0, especially at $\mathrm{pH} 5.0,6.0$, and 7.0.

Interestingly, the thickness of the clear serum formed at the bottom of the emulsions decreased with the increase of WSC concentration, indicating that the $\mathrm{pH}$ value was an 


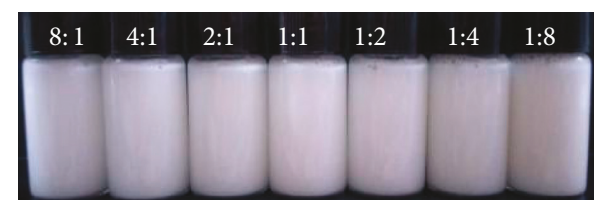

(a)

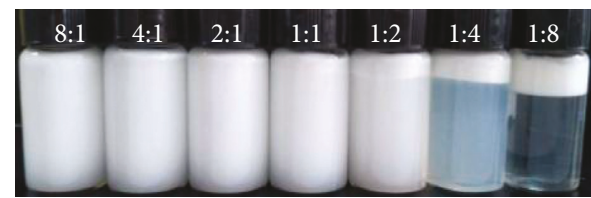

(c)

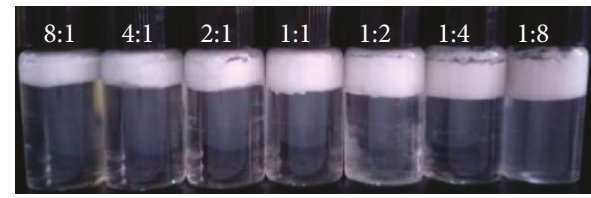

(e)

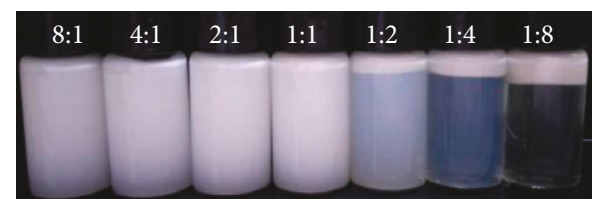

(b)

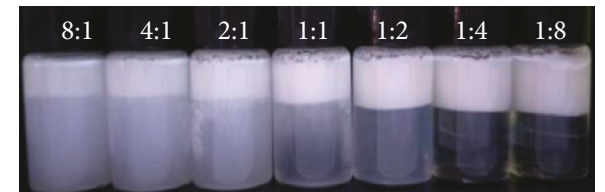

(d)

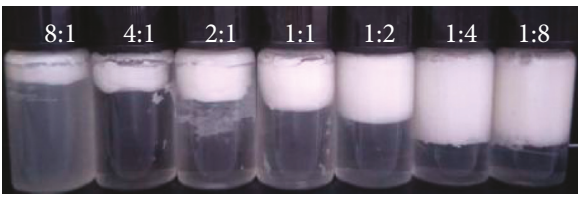

(f)

FIGURE 3: Photographs of BSA-WSC emulsions (containing $5 \% \mathrm{v} / \mathrm{v}$ oil) with different $\mathrm{pH}$ and biopolymer ratios $(R=\mathrm{BSA}:$ WSC $=8: 1-1$ : 8). (a) Fresh emulsions and (b-f) emulsions with different $\mathrm{pH}$ values 3.0, 4.0, 5.0, 6.0, and 7.0 after 20 -day storage at $25^{\circ} \mathrm{C}$.

important parameter, which was supposed to play key roles in regulating the electrostatic interaction of adjacent particles at the oil-water interface in the emulsion system. The electrical charge on the BSA-coated lipid droplets went from highly positive $\left(-\mathrm{NH}^{3+}\right)$ at low $\mathrm{pH}$ to neutral around the isoelectric point of BSA ( $\mathrm{pI}$ 4.7) and to highly negative $\left(-\mathrm{COO}^{-}\right)$at high $\mathrm{pH}[6]$. In our study, stable emulsions were obtained at low $\mathrm{pH}$ and high $\mathrm{BSA} / \mathrm{WSC}$ ratios, which was different from the literature reported by Li et al. [23], who found no improvement of emulsifying performance by BSA/sugar beet pectin (SBP) mixtures compared with the individual protein and polysaccharide at high $\mathrm{pH}$, while stable emulsions were obtained at low $\mathrm{pH}$ because of cooperative adsorption and extremely unstable emulsions were obtained at low and high BSA/SBP ratios because of bridging flocculation ratios. Additionally, Laplante et al. [24] reported that two types of phase separation in a model emulsion system containing whey protein isolate (WPI) and chitosan had a rapid syneresis at $\mathrm{pH} \leq 5.0$ due to the depletion flocculation between droplets and a lot more stable small gradient creaming with fine lipid dispersion at $\mathrm{pH} \geq 5.5$. Calero et al. reported that polysaccharides could stabilize emulsion droplets which were attributed to their ability to increase the viscosity of the continuous phase or their ability to promote formation of a gel network in the aqueous medium [2]. Furthermore, the $\mathrm{pH}$ affects the net charge on the molecule to become more positively or negatively charged due to the gain or loss of protons $\left(\mathrm{H}^{+}\right)$ in BSA and chitosan. Very recently, the interaction between BSA and chitosan was influenced by different concentrations of chitosan addition and different $\mathrm{pH}$ values [14]. Therefore, the mechanism of emulsion phase separation is not only very relevant to the nature of polysaccharides involved and protein-polysaccharide interactions but also influenced by $\mathrm{pH}$ values of the emulsion system.
Temperature is another important factor influencing the stability of $\mathrm{O} / \mathrm{W}$ and $\mathrm{W} / \mathrm{O}$ emulsions. In our study, emulsions at $\mathrm{pH} 5.0$ with different BSA : WSC ratios were used to investigate the storage stability of emulsions under different temperatures $\left(4,25\right.$, and $\left.37^{\circ} \mathrm{C}\right)$. As expected, the storage stability of all emulsions decreased with the increase of tested temperatures. Exaggerated phase separations are observed in Figure $4\left(25\right.$ and $\left.37^{\circ} \mathrm{C}\right)$, while the stability of emulsions containing BSA: WSC ratios from $8: 1$ to $1: 1$ was obtained after 20-day storage, respectively. The temperature-dependent characteristic is attributed to the higher temperature and the higher kinetic energy of the emulsifier particle's Brownian motion, thereby resulting in the redistribution of particles onto the $\mathrm{O} / \mathrm{W}$ interface and further increasing the tendency to coalesce and flocculate [25].

\subsection{Zeta Potential of Emulsions. BSA- or BSA/chitosan-} coated droplets were stable or aggregated which were supposed to be dependent on the balance of electrostatic repulsion and van der Waals force between the adjacent droplets of emulsions. The interaction in different concentrations of BSA- or BSA/chitosan-coated droplets was studied using zeta-potential measurements at different $\mathrm{pH}$ values, and the results are shown in Figure 5. As expected, charge on the BSA-coated lipid droplets was from positive, to neutral, to negative as the $\mathrm{pH}$ increased from 3.0 to 7.0 in the absence of chitosan. At pH 3.0, the charge on the droplets was similar to that in the presence of chitosan, possibly because of the strong electrostatic repulsion between the cationic chitosan molecules and cationic lipid droplets. However, the droplet charge was higher (more positive) in the presence of chitosan at higher $\mathrm{pH}$ values, which is presumably due to the adsorption of cationic chitosan molecules onto anionic patches on the droplet surfaces according to the previous research [26]. 


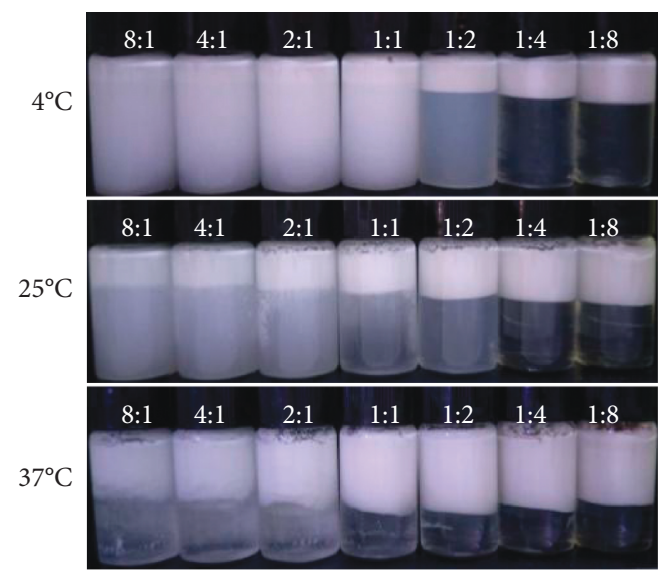

FIgURe 4: Photographs of pH 5.0 BSA-WSC emulsions (containing $5 \% \mathrm{v} / \mathrm{v}$ oil $)$ with different biopolymer ratios $(R=\mathrm{BSA}: \mathrm{WSC}=8$ : 1-1:8) after 20-day storage at (a) $4^{\circ} \mathrm{C}$, (b) $25^{\circ} \mathrm{C}$, and (c) $37^{\circ} \mathrm{C}$.

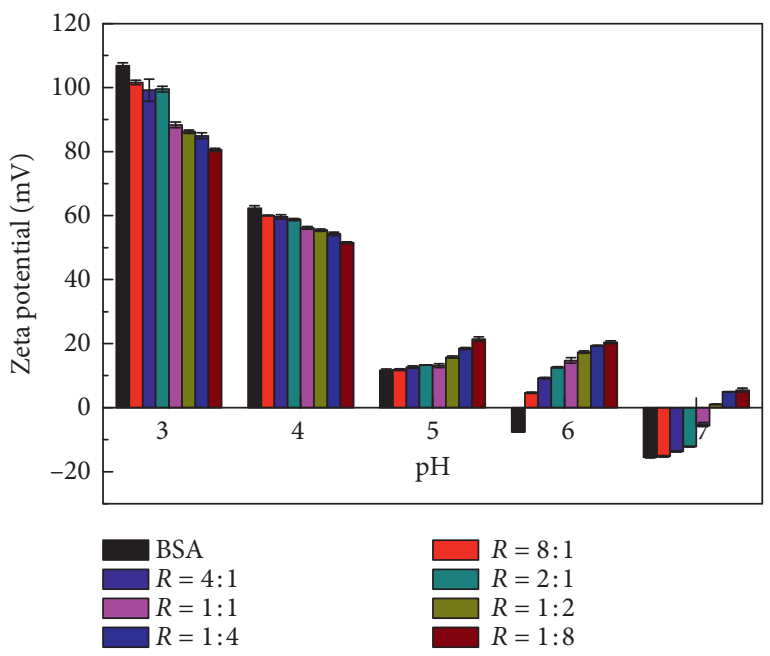

FIGURE 5: Zeta potential (mV) of emulsions (5\% v/v oil, pH 3.0-7.0) stabilized by BSA $(0.15 \%, w / v)$ and BSA-WSC mixtures with different biopolymer ratios $(R=\mathrm{BSA}: \mathrm{WSC})$ in acetate buffer $(0.1 \mathrm{~mol} / \mathrm{L})$ at $25^{\circ} \mathrm{C}$.

Generally, colloidal particles with zeta potential higher than $+30 \mathrm{mV}$ or lesser than $-30 \mathrm{mV}$ were considered to be very stable in the dispersion medium [27]. Herein, the zeta potential of BSA-stabilized emulsions was significantly higher than $+30 \mathrm{mV}$ at $\mathrm{pH} 3.0$ and 4.0, indicating that the emulsions were stable. However, the BSA-stabilized emulsions were unstable and aggregated at $\mathrm{pH}$ 5.0, 6.0, and 7.0 in the absence of chitosan. According to the theory given by Puhl et al. [27], droplets in BSA/WSC emulsions were stable at $\mathrm{pH} 3.0$ and 4.0 , and $R$ value ranged from $8: 1$ to $1: 1$, which was attributed to the fact that both BSA and chitosan possessed positive charges.

It can be seen from Figure 3 that, in the presence of chitosan, the emulsions were stable at lower $\mathrm{pH}$ values $(\mathrm{pH}$ 3.0 and 4.0) with lower BSA/WSC ratios; however, droplet aggregation was visually observed when $\mathrm{pH}$ values increased from 5.0 to 7.0 at all BSA/WSC ratios. These results are similar to those of the previous study reported by Yuan et al. and Speiciene et al. $[5,6]$, which were attributed to the charge neutralization, bridging flocculation, and chitosan precipitation at $\mathrm{pH} 6.5$.

3.4. Particle Size of Emulsions. The particle size measurement was further investigated for the influence of BSA and BSA/ chitosan ratio on the stability of emulsions at $\mathrm{pH} 3.0,4.0,5.0$, 6.0, and 7.0. As shown in Figure 6, there was no evidence of droplet aggregation in the particle size measurement when BSA and lower concentrations of chitosan were added ( $R$ from $8: 1$ to $1: 2$ ) at $\mathrm{pH} 3.0$ and 4.0 , which correlated with the visual observation of the emulsions (Figures $3(\mathrm{~b})$ and $3(\mathrm{c})$ ). BSA-stabilized emulsions were most stable at $\mathrm{pH} 3.0$ and 4.0 $(<250 \mathrm{~nm})$, followed by pH 7.0 (about $530 \mathrm{~nm}$ ) in the absence of chitosan; however, as discussed earlier, the emulsions were seriously unstable at $\mathrm{pH} 5.0$ and 6.0 (evidenced by the appearance of a transparent serum layer at $\mathrm{pH} 5.0$ and 6.0 , Figure 2) with larger mean particle diameter because of the flocculation that occurred due to low net charge [28]. At $\mathrm{pH} 3.0$ and 4.0, the mean particle diameter was chitosan concentration-dependent. The increase in mean particle diameter was observed by light scattering with the decrease of ratio values, which was expected that little interaction happened between BSA and chitosan under these $\mathrm{pH}$ conditions and the surface activity of chitosan molecules was weaker than that of the BSA molecules, or chitosan took much longer time to adsorb on the interface than the BSA molecules. This is similar to the result of Niu et al. [16]. Other studies also showed that proteins are much more surface active and have faster interfacial adsorption kinetics than polysaccharides [23]. The increase in the particle size of BSAWSC emulsions at $\mathrm{pH} 3.0$ and 4.0 is because of the depletion flocculation caused by excess chitosan addition when $R$ is from $1: 2$ to $1: 8$. At $\mathrm{pH} 6.0$, a significant large increase of droplets ( $>500 \mathrm{~nm}$, even up to more than $10 \mu \mathrm{m}$ ) happened even though small amounts of chitosan $(R=8: 1)$ were added to the BSA emulsions. Results of particle size were consistent with those of storage stability (Figures 2 and 3 ) and zeta potential (Figure 5). The lower stability of BSA/ WSC-coated emulsions at $\mathrm{pH}$ 5.0, 6.0, and 7.0 can be attributed to the various mechanisms discussed earlier, such as charge neutralization, bridging flocculation, chitosan precipitation, and the adsorption of cationic chitosan molecules to the droplet surfaces due to electrostatic attraction, which was described by Guzey and McClements [29].

3.5. Light Microscopy Observations. According to the literature [5], the emulsions were diluted $(1: 1)$ because the images of concentrated emulsion droplets were difficult to detect whether droplets were flocculated or just in close proximity, thus making the result uninformative. The optical microscopy images of sunflower oil emulsions are presented in Figure 7. It can be observed that emulsions prepared with $\mathrm{BSA} /$ chitosan $(R>1: 1)$ at $\mathrm{pH} 3.0$ and 4.0 yield smaller droplets and uniform emulsions, which is attributed to the fact that the interfacial tension of droplets declines by exerting electrostatic repulsion and/or steric hindrance between pairs of dispersed droplets comprised by BSA and 

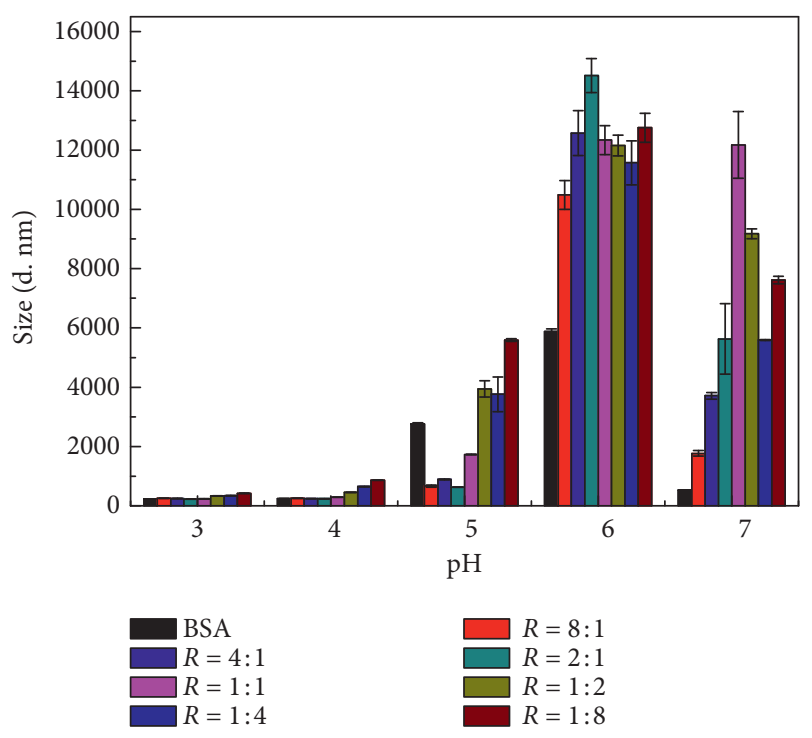

FIGUre 6: Particle size $(d, \mathrm{~nm})$ of emulsions ( $5 \% \mathrm{v} / \mathrm{v}$ oil, $\mathrm{pH} 3.0-7.0)$ stabilized by BSA $(0.15 \%$, w/v) and BSA-WSC mixtures with different biopolymer ratios $\left(R=\mathrm{BSA}\right.$ : WSC) in acetate buffer $(0.1 \mathrm{~mol} / \mathrm{L})$ at $25^{\circ} \mathrm{C}$.

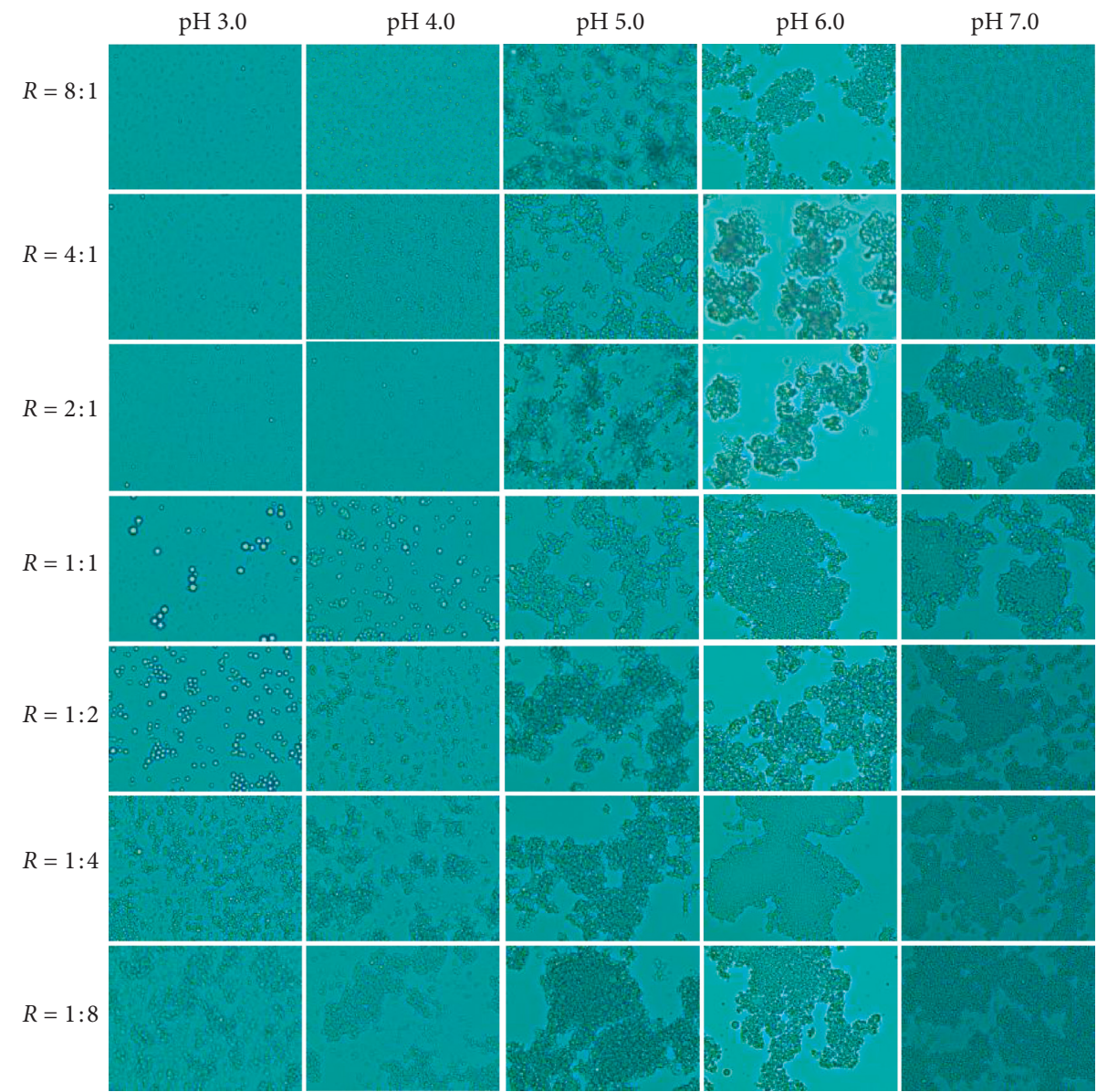

FIgURE 7: Micrographs with a 400-fold magnification of BSA/WSC emulsions (containing 5\% v/v oil) with different pH and different biopolymer ratios $(R=\mathrm{BSA}$ : WSC $)$.

chitosan. With the increase of chitosan concentration $(R$ from $1: 1$ to $1: 8)$ and $\mathrm{pH}$ value, larger emulsion droplets were observed, indicating that the coalescence and flocculation happened because chitosan self-aggregated due to the hydrophobicity, the self-aggregation intensified with the increase of chitosan concentration, and the 
deprotonation of cationic amines happened under a high $\mathrm{pH}$ condition $(\mathrm{pH}>\mathrm{pKa})$. Larger emulsion droplets were much less stable, and the results herein were correlated with the investigation of storage stability.

In the food systems containing lower polysaccharide contents $(\leq 0.1 \% \mathrm{w} / \mathrm{w})$, the physical stability is essentially regulated by the different interactions between different biopolymers, which have important consequences on emulsion stability $[9,30]$. Attractive and repulsive forces of polysaccharide (PS)-protein (P) interactions in food emulsions vary under different biopolymer structures and environmental conditions ( $\mathrm{pH}, \mathrm{P} / \mathrm{PS}$ ratio, and concentration of $\mathrm{PS}$ and $\mathrm{P}$ ). When attractive forces between $\mathrm{P}$ and PS predominate over P-P or PS-PS, they co-adsorb at the oil/water interface and steric repulsive forces between lipid droplets increase, thereby increasing the resulting emulsion stability (DLVO theory). Contrarily, P-PS incompatibility produces unfavorable interactions between the adsorbed $\mathrm{P}$ and PS layer in continuous phase, and phase separation happens because of depletion flocculation [31]. Chitosan addition could alter the secondary structure of BSA [14] and lead to a morphological dynamic process change [32]. The stable complexes were formed by chitosan and BSA via hydrophobic and electrostatic action which was influenced by $\mathrm{pH}, \mathrm{P} / \mathrm{PS}$ ratio, and temperature.

\section{Conclusions}

The purpose of this study was to investigate the stability of oil-in-water emulsions containing $5 \% \mathrm{v} / \mathrm{v}$ oil and $0.15 \% \mathrm{w} /$ $\mathrm{v}$ BSA, and various concentrations of chitosan were analyzed in detail using storage stability, zeta potential, particle size measurement, and microscopic observation. The results showed that $\mathrm{pH}$, protein/polysaccharide ratio, and temperature significantly influenced the physical stability of emulsions at lower $\mathrm{pH}$. The emulsion stability decreased as the test temperatures increased, and the storage stability of BSA/chitosan-coated oil emulsions was obtained when the ratio was from $8: 1$ to $1: 1$ under $4^{\circ} \mathrm{C}$ for 20 -day storage when $\mathrm{pH}$ values were 3.0 and 4.0. Droplet flocculation happened with the increase of chitosan addition and $\mathrm{pH}$ value. An ideal solid emulsifier is supposed to be inexpensive, easily preparative, nontoxic, biocompatible, and highly ecologically acceptable. The results obtained herein play a crucial role in promoting research on development of the novel emulsion and provide useful information on the application of food formulation using chitosan.

\section{Data Availability}

The data used to support the findings of this study are available from the corresponding author upon request.

\section{Conflicts of Interest}

The authors declare that there are no conflicts of interests regarding the publication of this article.

\section{Acknowledgments}

This study was supported by the Public Welfare Project of Zhejiang Province of China (2017C32008).

\section{References}

[1] D. B. Yuan, Y. Q. Hu, T. Zeng, S. W. Yin, C. H. Tang, and X. Q. Yang, "Development of stable pickering emulsions/oil powders and pickering HIPEs stabilized by gliadin/chitosan complex particles," Food \& Function, vol. 8, no. 6, pp. 2220-2230, 2017.

[2] N. Calero, J. Muñoz, P. W. Cox, A. Heuer, and A. Guerrero, "Influence of chitosan concentration on the stability, microstructure and rheological properties of $\mathrm{O} / \mathrm{W}$ emulsions formulated with high-oleic sunflower oil and potato protein," Food Hydrocolloids, vol. 30, no. 1, pp. 152-162, 2013.

[3] M. Destribats, M. Rouvet, C. Gehin-Delval, C. Schmitt, and B. P. Binks, "Emulsions stabilised by whey protein microgel particles: towards food-grade Pickering emulsions," Soft Matter, vol. 10, no. 36, pp. 6941-6954, 2014.

[4] T. Cserháti, E. Forgács, and G. Oros, "Biological activity and environmental impact of anionic surfactants," Environment International, vol. 28, no. 5, pp. 337-348, 2002.

[5] V. Speiciene, F. Guilmineau, U. Kulozik, and D. Leskauskaite, "The effect of chitosan on the properties of emulsions stabilized by whey proteins," Food Chemistry, vol. 102, no. 4, pp. 1048-1054, 2007.

[6] F. Yuan, Y. Gao, E. A. Decker, and D. J. McClements, "Modulation of physicochemical properties of emulsified lipids by chitosan addition," Journal of Food Engineering, vol. 114, no. 1, pp. 1-7, 2013.

[7] K. Gancz, M. Alexander, and M. Corredig, "Interactions of high methoxyl pectin with whey proteins at oil/water interfaces at acid pH," Journal of Agricultural and Food Chemistry, vol. 53, no. 6, pp. 2236-2241, 2005.

[8] S. Laplante, S. L. Turgeon, and P. Paquin, "Emulsion-stabilizing properties of chitosan in the presence of whey protein isolate: effect of the mixture ratio, ionic strength and $\mathrm{pH}$," Carbohydrate Polymers, vol. 65, no. 4, pp. 479-487, 2006.

[9] E. Dickinson, "Biopolymer interactions in emulsion systems: influences on creaming, flocculation, and rheology," ACS Symposium Series, vol. 650, no. 6, pp. 197-207, 1996.

[10] E. Dickinson and V. B. Galazka, "Emulsion stabilization by ionic and covalent complexes of $\beta$-lactoglobulin with polysaccharides," Food Hydrocolloids, vol. 5, no. 3, pp. 281-296, 1991.

[11] R. Yang, Y. Jiang, L. L. Xiu, and J. Y. Huang, "Effect of chitosan pre-soaking on the growth and quality of yellow soybean sprouts," Journal of the Science of Food and Agriculture, vol. 99, no. 4, pp. 1596-1603, 2019.

[12] T. Dimitrova, F. Leal-Calderon, T. D. Gurkov, and B. Campbell, "Surface forces in model oil-in-water emulsions stabilized by proteins," Advances in Colloid and Interface Science, vol. 108-109, no. 10, pp. 73-86, 2004.

[13] V. Rampon, C. Brossard, N. Mouhousriou, B. Bousseau, G. Llamas, and C. Genot, "The nature of the apolar phase influences the structure of the protein emulsifier in oil-inwater emulsions stabilized by bovine serum albumin. A frontsurface fluorescence study," Advances in Colloid and Interface Science, vol. 108-109, no. 10, pp. 87-94, 2004.

[14] G. Li, J. Huang, T. Chen, X. Wang, H. Zhang, and Q. Chen, "Insight into the interaction between chitosan and bovine 
serum albumin," Carbohydrate Polymers, vol. 176, pp. 75-82, 2017.

[15] T. Moschakis, B. S. Murray, and C. G. Biliaderis, "Modifications in stability and structure of whey protein-coated o/w emulsions by interacting chitosan and gum Arabic mixed dispersions," Food Hydrocolloids, vol. 24, no. 1, pp. 8-17, 2010.

[16] F. Niu, Y. Zhang, C. Chang et al., "Influence of the preparation method on the structure formed by ovalbumin/gum Arabic to observe the stability of oil-in-water emulsion," Food Hydrocolloids, vol. 63, pp. 602-610, 2017.

[17] S. Tcholakova, N. D. Denkov, and T. Danner, "Role of surfactant type and concentration for the mean drop size during emulsification in turbulent flow," Langmuir, vol. 20, no. 18, pp. 7444-7458, 2004.

[18] S. Tcholakova, N. D. Denkov, D. Sidzhakova, I. B. Ivanov, and B. Campbell, "Interrelation between drop size and protein adsorption at various emulsification conditions," Langmuir, vol. 19, no. 14, pp. 5640-5649, 2003.

[19] C. Wen, Q. Yuan, H. Liang, and F. Vriesekoop, "Preparation and stabilization of d-limonene pickering emulsions by cellulose nanocrystals," Carbohydrate Polymers, vol. 112, no. 2, pp. 695-700, 2014.

[20] S. M. Jafari, E. Assadpoor, Y. He, and B. Bhandari, "Re-coalescence of emulsion droplets during high-energy emulsification," Food Hydrocolloids, vol. 22, no. 7, pp. 1191-1202, 2008.

[21] Y.-H. Cho and D. J. McClements, "Theoretical stability maps for guiding preparation of emulsions stabilized by protein-polysaccharide interfacial complexes," Langmuir, vol. 25, no. 12, pp. 6649-6657, 2009.

[22] E. Dickinson, "Hydrocolloids at interfaces and the influence on the properties of dispersed systems," Food Hydrocolloids, vol. 17, no. 1, pp. 25-39, 2003.

[23] X. Li, Y. Fang, S. Al-Assaf, G. O. Phillips, and F. Jiang, "Complexation of bovine serum albumin and sugar beet pectin: stabilising oil-in-water emulsions," Journal of Colloid and Interface Science, vol. 388, no. 1, pp. 103-111, 2012.

[24] S. Laplante, S. Turgeon, and P. Paquin, "Effect of $\mathrm{pH}$, ionic strength, and composition on emulsion stabilising properties of chitosan in a model system containing whey protein isolate," Food Hydrocolloids, vol. 19, no. 4, pp. 721-729, 2005.

[25] B. P. Binks, "Particles as surfactants-similarities and differences," Current Opinion in Colloid \& Interface Science, vol. 7, no. 1-2, pp. 21-41, 2002.

[26] Y.-H. Hong and D. J. McClements, "Modulation of $\mathrm{pH}$ sensitivity of surface charge and aggregation stability of protein-coated lipid droplets by chitosan addition," Food Biophysics, vol. 2, no. 1, pp. 46-55, 2007.

[27] A. Puhl, M. Fagundes, K. Santos et al., "Preparation and characterization of polymeric nanoparticles loaded with the flavonoid luteolin, by using factorial design," International Journal of Drug Delivery, vol. 3, no. 4, pp. 683-698, 2011.

[28] C. Schmitt and S. L. Turgeon, "Protein/polysaccharide complexes and coacervates in food systems," Advances in Colloid and Interface Science, vol. 167, no. 1-2, pp. 63-70, 2011.

[29] D. Guzey and D. J. McClements, "Formation, stability and properties of multilayer emulsions for application in the food industry," Advances in Colloid and Interface Science, vol. 128-130, pp. 227-248, 2006.

[30] P. Joly, J.-C. Roujeau, J. Benichou et al., "A comparison of oral and topical corticosteroids in patients with bullous pemphigoid," New England Journal of Medicine, vol. 346, no. 5, pp. 321-327, 2002.
[31] J. Chen and E. Dickinson, "Protein/surfactant interfacial interactions part 3. Competitive adsorption of protein + surfactant in emulsions," Colloids and Surfaces A: Physicochemical and Engineering Aspects, vol. 101, no. 1, pp. 77-85, 1995.

[32] D. Agudelo, L. Bekale, and H. A. Tajmir-Riahi, "Effect of polymer molecular weight on chitosan-protein interaction," Colloids and Surfaces B: Biointerfaces, vol. 125, pp. 309-317, 2015. 


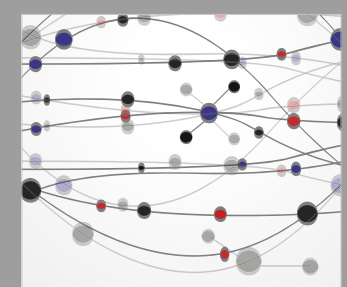

The Scientific World Journal
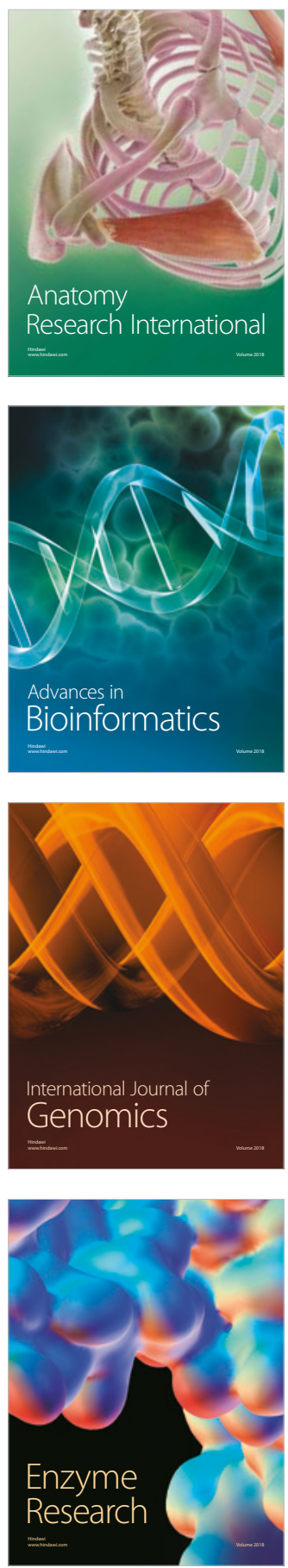
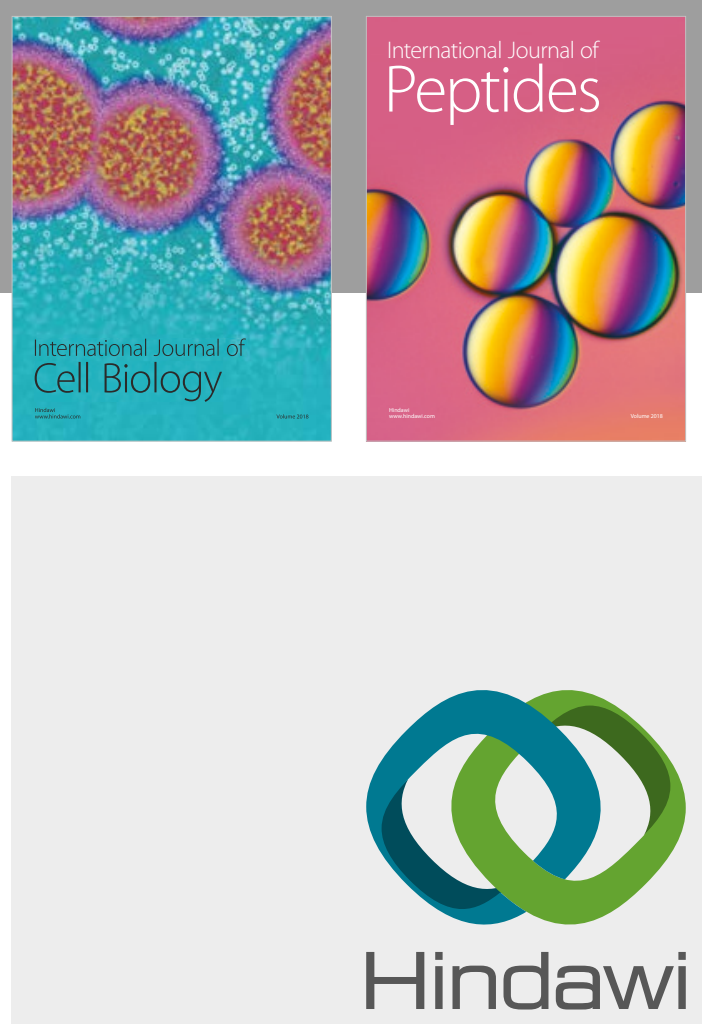

Submit your manuscripts at

www.hindawi.com
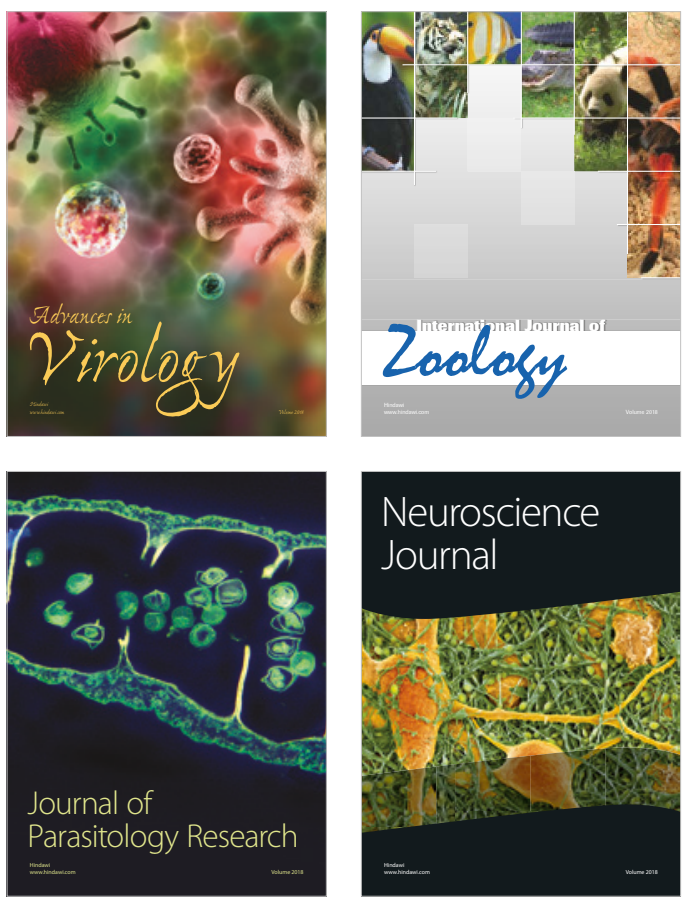
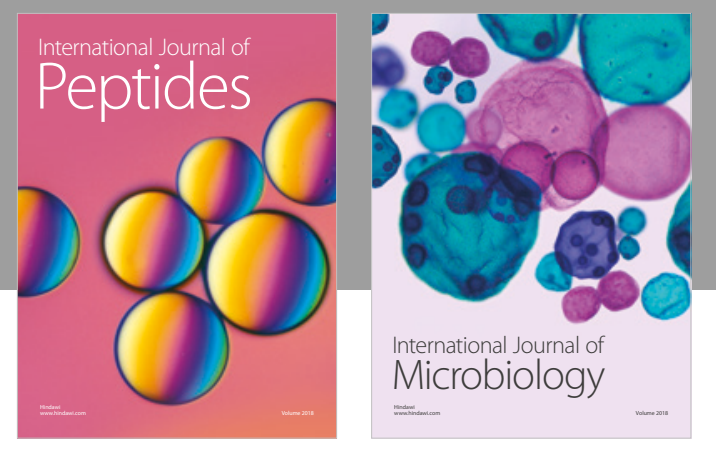

nternational Journal of Microbiology
Journal of
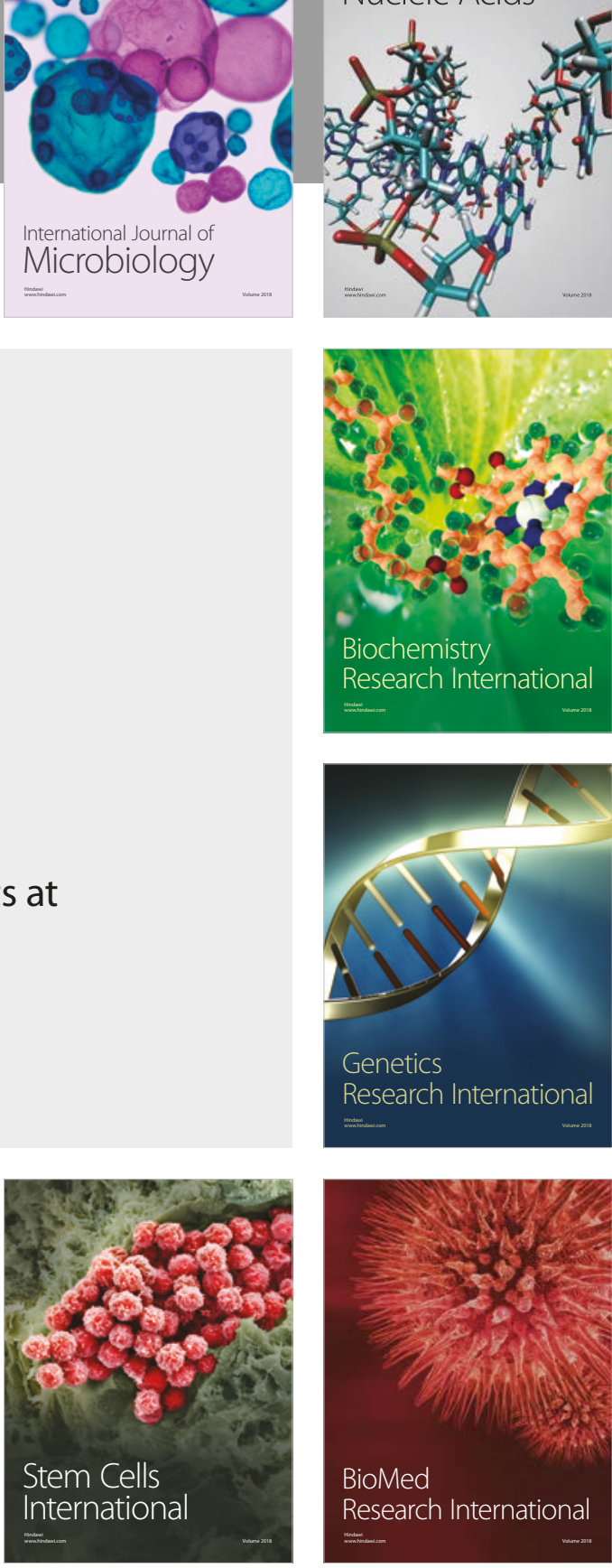
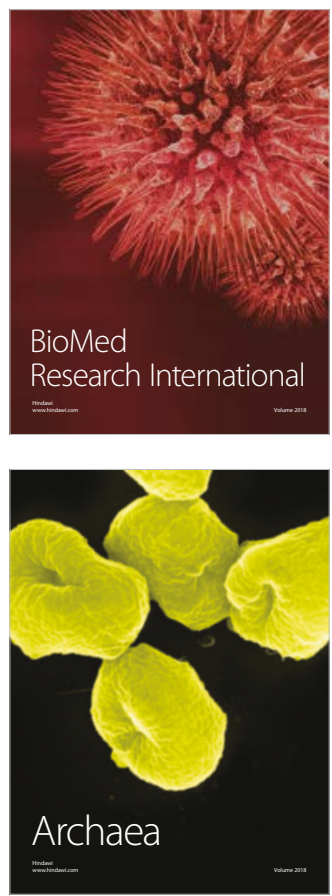